\title{
HYPERPARATHYROIDISM-JAW TUMOUR SYNDROME
}

\author{
S Hafeez, WJ Kalk, Aisha Saqib, L Izatt, A W Barrett
}

Endocrinology Department, Medway Maritime Hospital, Kent ,England.(saba.hafeez@medway.nhs.uk)

\section{Introduction:}

Case Report
The hyperparathyroidism-jaw tumour syndrome is a rare autosomal,dominantly inherited disorder characterized by neoplastic or cystic leisons in parathyroid glands, jaws and the kidneys.Disease causing mutations have been localized in tumor suppreser gene CDC73.

With approimately200 reported cases in literature this condition remains a challenge both diagnostically and in guiding further managent.

17 year old scholar was seen by the maxillofacial department, in Sept 2015, with 2 painless swellings in his mouth, present for 2-3 months. Dental X-ray (OPG) showed resorption of bone at the sites of the swellings. Routine blood tests showed serum corrected calcium of $4.12 \mathrm{mmol} / 1$ (16.48 mg/dl), plasma PTH of $628 \mathrm{ng} / \mathrm{l}(10-65)$ and normal renal and thyroid function. He had experienced significant polyuria and polydipsia for at least 2-3 years prior to this presentation. A CT scan of neck showed $2.5 \mathrm{~cm} \times 2 \mathrm{~cm}$ right lower lobe parathyroid adenoma; ultrasound scan of his kidneys was normal. The tumour was resected: histology confirmed a benign parathyroid adenoma. There was no family history of any tumours Post-operatively the patient developed severe and prolonged "hungry bone syndrome". Plasma PTH levels are now normal.

Soon after the parathyroidectomy the maxillary swellings were biopsied. The histology showed spindle cells, osteoclast giant cells and substantial bone formation.

Genetic tests showed the characteristic mutation in the CDC73 gene. Mother is not a carrier; his father is currently awaiting genetic testing.

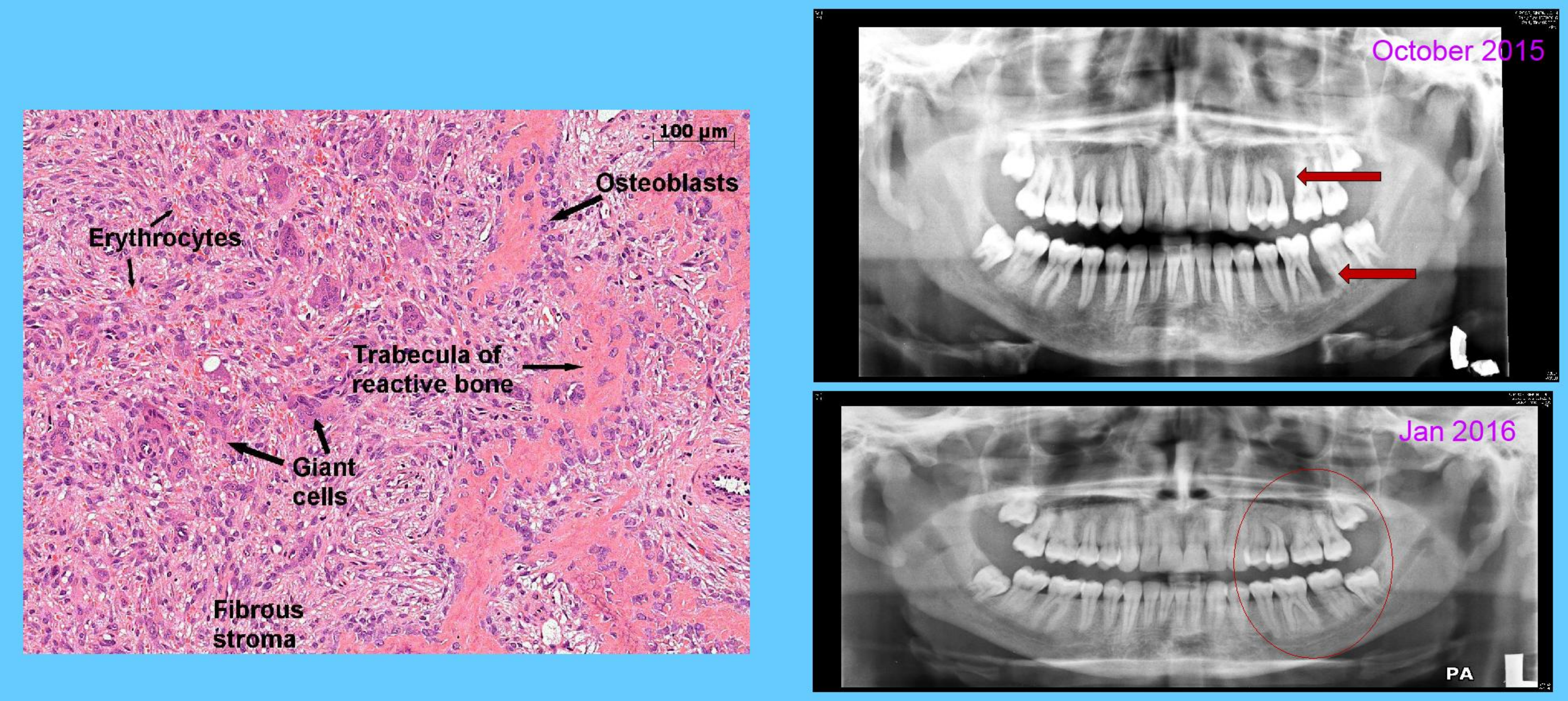

Healing of bony erosions can be noted following parathyroidectomy

Conclusions:

1. In our patient Hyperparathyroidism proceeded the jaw tumours by several years. Hence genetic testing should be considered in young patients with primary hyperparathyroidism.

2. Presence of osteoclast giant cell granulomas was an unusual feature histologically, in contrast to the more typical cemento-ossifying fibromas.

3. Post parathyroidectomy there was subjective regression of only one, mandibular, swelling despite both tumours having the same histology.

4. There appears to have been radiological improvemnt at both tumour sites

5. Spontaneous mutations can be a cause of disease process in the absence of positive family history.

6. Follow up in our patient will include serial calcium checks and renal and liver ultrasound studies.

\section{References:}

